\title{
EFFECTS OF VIRGIN COCONUT OIL AND LAURIC ACID "WITH OR WITHOUT 5-FLUOROURACIL" ON DIMETHYLHYDRAZINE- INDUCED HEPATOTOXICITY IN MALE RATS
}

\author{
Adel A. El-Bagoury ${ }^{1}$; Hala G. El-Tantawi ${ }^{2}$; Sabry A. El-Naggar ${ }^{3 *}$; \\ Amel M. Kwilla ${ }^{\mathbf{1}}$; Amal M. Khalaf ${ }^{1}$ \\ ${ }^{1}$ Home Economics Department, Faculty of Specific Education, Tanta University \\ ${ }^{2}$ Zoology Department, Faculty of Science, Aim Shams University, Cairo, Egypt \\ ${ }^{3}$ Zoology Department, Faculty of Science, Tanta University, Gharbia, Egypt
}

\begin{abstract}
Article History:
Received: 02 May 2019

Revised: 09 June 2019

Accepted: 12 June 2019

Published Online:

22 June 2019

Keywords:

5-Fluorouracil

Dimethylhydrazine

Hepatotoxicity

Lauric acid

Virgin coconut oil

*Correspondence:

Sabry El-Naggar

Zoology Department, Faculty of Science, Tanta University

Gharbia, Egypt

E-mail:

sabry.elnaggar@science.tanta. edu.eg
\end{abstract}

\begin{abstract}
Dimethylhydrazine (DMH) is highly toxic for the different body organs, including the liver. The current study aimed to investigate the potential protective role of virgin coconut oil (VCO) and lauric acid (LA) in presence/absence of a chemotherapy drug "5-fluorouracil (5-FU)" against the hepatoxicity induced by $\mathrm{DMH}$ in male rats (Rattus norvegicus). Ninety rats were randomly divided into nine groups $(\mathrm{n}=10)$. (G1) control group; (G2) rats received $4 \mathrm{~mL} \mathrm{VCO/kg} \mathrm{body} \mathrm{weight} \mathrm{(b.wt),} \mathrm{orally/day}$ after day for six weeks starting from week 13; (G3) rats received LA (200 mg/kg b.wt), orally/day after day for six weeks as in G2; (G4) rats were injected subcutaneously (s.c.) with $\mathrm{DMH}$ (20 mg/kg b.wt), once/week for the first six weeks; (G5) rats received $\mathrm{DMH}$ as in $\mathrm{G} 4$ and intraperitoneally (i.p.) injected with 5 -FU (75 mg/kg b.wt), once/week starting from week 13 for three successive weeks; (G6) rats received DMH and VCO as in G4 and G2, respectively; (G7) rats received DMH and LA as in G4 and $\mathrm{G} 3$, respectively; (G8) rats received $\mathrm{DMH}, 5-\mathrm{FU}$, and VCO as in G4, G5, and G2, respectively; (G9) rats received DMH, 5-FU, and LA as in G4, G5, and G3, respectively. The results showed that DMH injection caused oxidative stress and histopathological alterations in the liver tissue, as well as dyslipidaemia. However, treatment of male rats with VCO or LA in presence/absence of 5-FU reduced significantly the DMHinduced hepatotoxicity.
\end{abstract}

\section{INTRODUCTION}

A highly toxic agent "1,2-dimethylhydrazine dihydrochloride (DMH)" exists in tobacco, and affects several body organs including the liver ${ }^{[1,2]}$. It is metabolized in the liver and produces highly reactive carbonium ions and alkyl free radicals, which severely damage the liver causing necrosis and fatty infiltration ${ }^{[3,4]}$. Furthermore, a previous study showed that oral administration of DMH induced alterations in the composition of the intestinal brush border membranes and the intestinal absorptive functions in mice $^{[5]}$. The azoxymethane is a metabolite of 
$\mathrm{DMH}$ that is activated in the liver by oxidation to produce reactive compounds essential for chemical carcinogenesis being brought to the colon ${ }^{[6]}$. In addition, the azoxymethane causes hepatocyte proliferation, a preneoplastic change that alters hepatocytes ${ }^{[7,8]}$.

Chemotherapy is a chemical agent used to treat cancer and prevent cancer cell progression; however, it does not distinguish between normal and cancer cells ${ }^{[9]}$. Toxicity and therapeutic resistance post of the treatment are two major obstacles for successful cancer chemotherapy translated from bench to bed. The chemotherapeutic agent "5-Fluorouracil (5-FU)" is widely used in the treatment of a range of cancers including colorectal, breast, head, and neck $^{[10]}$. The $5-\mathrm{FU}$ is activated by thymidine phosphorylase into 5-fluoro-2'-deoxyuridine5'-monophosphate (5-FdUMP) and acts during the $S$ phase of the cell cycle ${ }^{[11]}$. The 5-FdUMP inhibits thymidylate synthase, leading to prevention of the DNA synthesis, then cell death. Furthermore, 5-FU is also converted to 5-fluorouridine monophosphate that interfered with RNA processing and function $^{[11]}$.

Combination treatment of natural compounds with chemotherapeutic agents (anti-cancer drugs) might increase the antitumour effect of the chemotherapeutic agents, especially in highly invasive tumours. In addition, treatment with the natural compounds might reduce the cytotoxic side effects of the chemotherapeutic agent on normal cells ${ }^{[12,13]}$. Virgin coconut oil (VCO) is the oil extracted from the fresh coconut kernel through natural or mechanical procedures. VCO has several polyphenolic antioxidants such as caffeic acid, syringic acid, catechin, and epigallocatechin ${ }^{[14]}$. It has been reported that the antioxidant activity of VCO is higher than that of refined coconut oil, and its supplementation has beneficial effects on blood lipids by reducing the hepatic lipogenesis and increasing the formation of bile acids ${ }^{[14,15]}$. In addition, the coconut oil contains high amount of lauric acid (LA), also called n-dodecanoic acid, which is a medium-chain fatty acid that forms monolaurin in the human or animal body ${ }^{[16]}$. Previous studies have demonstrated many beneficial biological effects of $\mathrm{LA}^{[17]}$. It showed antineoplastic properties and induced apoptosis in in colon cancer cell line ${ }^{[18]}$. Also, LA suppressed acne inflammation through inhibiting the nuclear factor- $\kappa \mathrm{B}$ activation, as well as the expression of cyclooxygenase- 2 and proinflammatory cytokines ${ }^{[19]}$. LA was also associated with beneficial effects on the cardiovascular system due to its ability to increase the high-density lipoproteins (HDL) in healthy women and men ${ }^{[20]}$, as well as reduce the blood pressure and heart rate in hypertensive rats ${ }^{[21]}$. Therefore, the present study aimed to evaluate the potential protective effects of $\mathrm{VCO}$ and LA, in presence/absence of 5-FU against the hepatotoxicity induced by $\mathrm{DMH}$ in male rats.

\section{MATERIAL AND METHODS Chemicals}

The DMH powder was purchased from Sigma Pharmaceutical Industries (Cairo, Egypt). The 5-FU ampules (250 mg/ampule; EBEWE Pharma Ges. m.b.H. NFg. KG, Unterach, Austria) were purchased from the local pharmacy. The VCO and LA were purchased from Cornell Lab (Giza, Egypt).

\section{Animals}

Ninety healthy male Sprague Dawley rats, 6-week-old (80-100 g), were obtained from Theodor Bilharis Institute (Imbaba, Giza, Cairo, Egypt) and used in the current study after acclimatisation for one week on the laboratory conditions before being divided into the groups. They were maintained under standard laboratory conditions $\left(22 \pm 1{ }^{\circ} \mathrm{C}\right.$ and $55 \pm 5 \%$ relative humidity) and given the rodents food pellets (Egy Vet Care, El-Mahalla El-Kubra, Gharbia, Egypt) and water ad libitum. The animals were humanely treated and the experimental design was approved by the animal care committee at the Zoology Department, Faculty of Science, Tanta University, prior to perform the experiments $(1 / 2018)$. 


\section{Experimental design}

Rats were randomly divided into nine groups $(\mathrm{n}=10)$. Group1 (G1) was severed as a control group. It did not receive any treatment, but handled as other treated groups (i.e. it received sterile normal saline " $0.9 \%$ " by injection, as well as distilled water by gavage). Group 2 (G2): rats received $4 \mathrm{~mL} \mathrm{VCO} / \mathrm{kg}$ body weight (b.wt), orally/day after day for six weeks starting from week 13. Group 3 (G3): rats received LA (200 mg/kg b.wt), orally/day after day for six weeks as in G2. Group 4 (G4): rats were subcutaneously (s.c.) injected with DMH $(20 \mathrm{mg} / \mathrm{kg}$ b.wt), once/week for the first six weeks. Group 5 (G5): rats received $\mathrm{DMH}$ as in $\mathrm{G} 4$ and intraperitoneally (i.p.) injected with 5 -FU $(75 \mathrm{mg} / \mathrm{kg}$ b.wt.), once/week starting from week 13 for three successive weeks. Group 6 (G6): rats received $\mathrm{DMH}$ as in $\mathrm{G} 4$ and treated with VCO as in G2. Group 7 (G7): rats received $\mathrm{DMH}$ as in G4 and treated with LA as in G3. Group 8 (G8): rats received DMH as in G4, then treated with 5-FU and $\mathrm{VCO}$ as in G5 and G2, respectively. Group 9 (G9): rats received DMH as in G4, then treated with 5-FU and LA as in G5 and G3, respectively. All rats were killed after 18 weeks under light diethyl ether anaesthesia.

\section{Blood and tissue sampling}

Blood samples were individually collected from rats of the different groups at the time of killing the animals, left to coagulate at room temperature, and then centrifuged to separate serum. The clear non-haemolysed serum was quickly removed and kept at $-20^{\circ} \mathrm{C}$ till used for biochemical analyses. Liver was immediately removed, cleaned, and cut into small pieces. Liver tissue specimens were fixed in $10 \%$ neutral buffered formalin for 24 hours to carry out the histopathological examination. Other small pieces of the liver $(0.5 \mathrm{~g})$ were homogenised in $5 \mathrm{~mL}$ of $0.9 \% \mathrm{NaCl}$. The obtained homogenate was kept in deep freezer at $-20^{\circ} \mathrm{C}$ till used for evaluating the liver oxidant/antioxidant biomarkers.

\section{Biochemical analyses}

The activities of serum alanine aminotransferase (ALAT), serum aspartate aminotransferase (ASAT), liver superoxide dismutase (SOD), and liver catalase (CAT) were colorimetrically determined by using the Biodiagnostic kits (Giza, Egypt) according to the manufacturer's instruction. In addition, the concentrations of serum total protein, albumin, total bilirubin, total cholesterol, triacylglycerols, and low-density lipoprotein-cholesterol (LDL-C), as well as liver reduced glutathione (GSH) and malondialdehyde (MDA), were colorimetrically determined by using the Biodiagnostic kits according to the manufacturer's instruction.

\section{Histological assay}

The fixed specimens of the liver were washed to remove the excess of fixative, and dehydrated in ascending series of ethyl alcohol. After dehydration, tissue samples were embedded in paraffin wax, sectioned at $5 \mu \mathrm{m}$, and stained with haematoxylin and $\operatorname{eosin}^{[22]}$ for histological examination. Photomicrographs were taken using a camera attached to a Leica DM LS2 microscope (Leica Microsystems, Wetzlar, Germany) at the Regional Centre for Mycology and Biotechnology, El-Azhar University (Cairo, Egypt).

\section{Statistical analysis}

Group's data expressed as means \pm standard deviation. Statistical analysis was performed with $t$-test using GraphPad Prism version 6.0 for windows (GraphPad software; San Diego, CA, USA). $P<0.05$ was considered statistically significant.

\section{RESULTS}

Effects of VCO and LA "with/without 5-FU" on serum and liver biochemical parameters of DMH-treated male rats

The male rats treated with VCO alone or LA alone did not show any significant changes in all biochemical parameters that were measured in the serum and liver, as compared with the control group $(P>0.05$, 
Tables 1-3). However, DMH-treated rats showed a significant increase $(P<0.05$, compared with the control group) in: (a) serum ALAT and ASAT activities, serum total bilirubin concentration, and liver MDA concentration indicating liver injury (Tables 1 and 3), (b) serum total cholesterol, triacylglycerols, and LDL-C concentrations indicating dyslipidaemia (Table 2). On the other hand, the DMHtreated rats had a significant decrease in the liver antioxidants indicating oxidative stress (Table 3). The 5-FU alone, VCO alone, and LA alone alleviated significantly $(P<0.05)$ the $\mathrm{DMH}$-induced liver injury/oxidative stress and blood dyslipidaemia, but with a lesser extent than 5-FU + VCO and 5-FU + LA as shown in tables " $1-3$ ". In addition, the modulatory activity of VCO against DMHtoxicity is a subtle higher than that of LA (Tables 1-3).

Table 1: Effects of virgin coconut oil (VCO) and lauric acid (LA) "with/without 5-Fluorouracil (5-FU)" on liver functions of dimethylhydrazine (DMH)-treated male rats.

\begin{tabular}{lccccc}
\hline & $\begin{array}{c}\text { ALAT activity } \\
(\mathrm{IU} / \mathrm{L})\end{array}$ & $\begin{array}{c}\text { ASAT activity } \\
(\mathrm{IU} / \mathrm{L})\end{array}$ & $\begin{array}{c}\text { Total protein } \\
(\mathrm{g} / \mathrm{dL})\end{array}$ & $\begin{array}{c}\text { Albumin } \\
(\mathrm{g} / \mathrm{dL})\end{array}$ & $\begin{array}{c}\text { Total bilirubin } \\
(\mathrm{mg} / \mathrm{dL})\end{array}$ \\
\cline { 2 - 6 } Control & $128.0 \pm 1.4$ & $142.5 \pm 1.4$ & $6.80 \pm 0.07$ & $3.70 \pm 0.14$ & $0.18 \pm 0.01$ \\
VCO & $117.5 \pm 1.6$ & $146.5 \pm 0.7$ & $6.95 \pm 0.08$ & $3.50 \pm 0.12$ & $0.19 \pm 0.01$ \\
$\mathrm{LA}$ & $119.5 \pm 2.0$ & $144.5 \pm 2.0$ & $7.00 \pm 0.14$ & $3.90 \pm 0.14$ & $0.21 \pm 0.02$ \\
$\mathrm{DMH}$ & $188.5 \pm 0.5^{\mathrm{a}}$ & $193.5 \pm 1.2^{\mathrm{a}}$ & $6.60 \pm 0.10$ & $3.65 \pm 0.10$ & $0.27 \pm 0.03^{\mathrm{a}}$ \\
$\mathrm{DMH}+5-\mathrm{FU}$ & $196.5 \pm 4.9$ & $203.0 \pm 1.2$ & $6.75 \pm 0.40$ & $3.60 \pm 0.40$ & $0.28 \pm 0.02$ \\
$\mathrm{DMH}+\mathrm{VCO}$ & $157.0 \pm 1.9^{\mathrm{b}}$ & $178.5 \pm 1.1$ & $6.95 \pm 0.07$ & $3.70 \pm 0.15$ & $0.19 \pm 0.04^{\mathrm{b}}$ \\
$\mathrm{DMH}+\mathrm{LA}$ & $166.0 \pm 3.1^{\mathrm{b}}$ & $180.5 \pm 1.7$ & $7.02 \pm 0.06$ & $3.63 \pm 0.11$ & $0.23 \pm 0.03$ \\
$\mathrm{DMH}+5-\mathrm{FU}+\mathrm{VCO}$ & $147.5 \pm 2.0^{\mathrm{b}}$ & $164.5 \pm 1.0^{\mathrm{b}}$ & $6.95 \pm 0.20$ & $3.80 \pm 0.13$ & $0.20 \pm 0.02^{\mathrm{b}}$ \\
$\mathrm{DMH}+5-\mathrm{FU}+\mathrm{LA}$ & $157.5 \pm 4.9^{\mathrm{b}}$ & $171.3 \pm 1.4^{\mathrm{b}}$ & $6.80 \pm 0.14$ & $3.80 \pm 0.07$ & $0.21 \pm 0.01^{\mathrm{b}}$ \\
\hline
\end{tabular}

Results are expressed as means \pm standard deviation $(\mathrm{n}=5)$. ALT: alanine aminotransferase, ASAT: aspartate aminotransferase. ${ }^{a} P<0.05$, significantly different from the control group; ${ }^{\mathrm{b}} P<0.05$, significantly different from the DMH-treated group.

Table 2: Effects of virgin coconut oil (VCO) and lauric acid (LA) "with/without 5-Fluorouracil (5-FU)" on serum lipid profile of dimethylhydrazine (DMH)-treated male rats.

\begin{tabular}{lccc}
\hline & $\begin{array}{c}\text { Total cholesterol } \\
(\mathrm{mg} / \mathrm{dL})\end{array}$ & $\begin{array}{c}\text { Triacylglycerols } \\
(\mathrm{mg} / \mathrm{dL})\end{array}$ & $\begin{array}{c}\text { LDL-C } \\
(\mathrm{mg} / \mathrm{dL})\end{array}$ \\
\cline { 2 - 4 } Control & $62.5 \pm 0.7$ & $31.5 \pm 2.1$ & $43.0 \pm 1.4$ \\
VCO & $64.5 \pm 1.0$ & $30.5 \pm 3.5$ & $43.6 \pm 1.6$ \\
LA & $66.5 \pm 0.7$ & $36.0 \pm 0.7$ & $44.5 \pm 1.2$ \\
DMH & $105.0 \pm 1.4^{\mathrm{a}}$ & $99.0 \pm 1.4^{\mathrm{a}}$ & $55.4 \pm 0.8^{\mathrm{a}}$ \\
$\mathrm{DMH}+5-\mathrm{FU}$ & $97.5 \pm 1.1^{\mathrm{b}}$ & $83.5 \pm 2.0^{\mathrm{b}}$ & $51.3 \pm 1.0^{\mathrm{b}}$ \\
$\mathrm{DMH}+\mathrm{VCO}$ & $86.5 \pm 2.2^{\mathrm{b}}$ & $49.0 \pm 1.3^{\mathrm{b}}$ & $48.6 \pm 1.3^{\mathrm{b}}$ \\
$\mathrm{DMH}+\mathrm{LA}$ & $91.1 \pm 1.4^{\mathrm{b}}$ & $55.0 \pm 0.7^{\mathrm{b}}$ & $49.7 \pm 1.2^{\mathrm{b}}$ \\
$\mathrm{DMH}+5-\mathrm{FU}+\mathrm{VCO}$ & $66.0 \pm 1.2^{\mathrm{b}}$ & $44.0 \pm 1.4^{\mathrm{b}}$ & $45.8 \pm 0.3^{\mathrm{b}}$ \\
DMH + 5-FU + LA & $69.0 \pm 1.1^{\mathrm{b}}$ & $50.5 \pm 2.1^{\mathrm{b}}$ & $46.6 \pm 0.6^{\mathrm{b}}$ \\
\hline
\end{tabular}

Results are expressed as means \pm standard deviation $(n=5)$. LDL-C: low-density lipoprotein-cholesterol. ${ }^{\mathrm{a}} P<0.05$, significantly different from the control group; ${ }^{\mathrm{b}} P<0.05$, significantly different from the DMH-treated group. 
Table 3: Effects of virgin coconut oil (VCO) and lauric acid (LA) "with/without 5-Fluorouracil (5-FU)" on the antioxidant/oxidant biomarkers in liver tissues of dimethylhydrazine $(\mathrm{DMH})$-treated male rats.

\begin{tabular}{lcccc}
\hline & $\begin{array}{c}\text { SOD activity } \\
(I U / m g \text { tissue })\end{array}$ & $\begin{array}{c}\text { CAT activity } \\
(\mu \mathrm{M} / \mathrm{min} / \mathrm{mg} \text { tissue })\end{array}$ & $\begin{array}{c}\text { GSH } \\
(\mu \mathrm{g} / \mathrm{g} \text { tissue })\end{array}$ & $\begin{array}{c}\text { MDA } \\
(\mathrm{nmol} / \mathrm{g} \text { tissue })\end{array}$ \\
\cline { 2 - 5 } Control & $21.1 \pm 0.4$ & $109.5 \pm 0.7$ & $13.0 \pm 0.6$ & $121.0 \pm 1.7$ \\
VCO & $22.1 \pm 0.5$ & $99.6 \pm 1.6^{\mathrm{a}}$ & $11.9 \pm 0.9$ & $127.2 \pm 2.5$ \\
$\mathrm{LA}$ & $23.8 \pm 0.8$ & $110.9 \pm 1.0$ & $12.9 \pm 0.3$ & $128.6 \pm 2.0$ \\
$\mathrm{DMH}$ & $10.6 \pm 1.3^{\mathrm{a}}$ & $81.2 \pm 2.4^{\mathrm{a}}$ & $8.0 \pm 1.0^{\mathrm{a}}$ & $164.2 \pm 3.4^{\mathrm{a}}$ \\
$\mathrm{DMH}+5-\mathrm{FU}$ & $15.4 \pm 0.8^{\mathrm{b}}$ & $87.9 \pm 2.2^{\mathrm{b}}$ & $9.1 \pm 0.9$ & $156.7 \pm 1.6^{\mathrm{b}}$ \\
$\mathrm{DMH}+\mathrm{VCO}$ & $17.3 \pm 0.7^{\mathrm{b}}$ & $98.5 \pm 2.9^{\mathrm{b}}$ & $12.0 \pm 0.5^{\mathrm{b}}$ & $141.1 \pm 0.6^{\mathrm{b}}$ \\
$\mathrm{DMH}+\mathrm{LA}$ & $20.1 \pm 0.2^{\mathrm{b}}$ & $90.5 \pm 1.0^{\mathrm{b}}$ & $11.0 \pm 0.5^{\mathrm{b}}$ & $147.7 \pm 1.2^{\mathrm{b}}$ \\
$\mathrm{DMH}+5-\mathrm{FU}+\mathrm{VCO}$ & $19.3 \pm 0.5^{\mathrm{b}}$ & $102.7 \pm 2.4^{\mathrm{b}}$ & $12.7 \pm 0.3^{\mathrm{b}}$ & $133.6 \pm 1.0^{\mathrm{b}}$ \\
DMH + 5-FU + LA & $20.9 \pm 0.6^{\mathrm{b}}$ & $99.6 \pm 1.7^{\mathrm{b}}$ & $11.7 \pm 0.1^{\mathrm{b}}$ & $143.8 \pm 2.9^{\mathrm{b}}$ \\
\hline
\end{tabular}

Results are expressed as means \pm standard deviation $(n=5)$. SOD: superoxide dismutase, CAT: catalase, GSH: reduced glutathione, MDA: malondialdehyde. ${ }^{a} P<0.05$, significantly different from the control group; ${ }^{\mathrm{b}} P<0.05$, significantly different from the DMH-treated group.

Effects of VCO and LA "with/without 5-FU" on liver histological structure of DMH-treated male rats

Examining of liver sections of the control group, stained by routine haematoxylin and eosin, revealed typical hepatic architecture of radial cords of polyhedral hepatocytes radiating from a central vein. The hepatic cells appeared with rounded, centrally located and vesicular nuclei. Blood sinusoids run parallel to the hepatic cords (Figure 1a). Slight congestion of the central veins and dilatation of the sinusoids were noticed in the hepatic tissue of the VCO-treated group (Figure 1b). The hepatocytes of the LA-treated group were nearly normal with few inflammatory cells in the portal spaces (Figure 1c). DMHtreated rats had a marked loss of the hepatic lobular structure. Apparent vacuolar degeneration of hepatocytes with pyknotic nuclei and congested central vein were also seen (Figure 2a). Treatments with VCO or LA modulated the histological changes induced by $\mathrm{DMH}$ in the liver (Figures 2b and 2c). In these two groups, the hepatocytes were nearly normal in appearance, with no signs of focal necrosis or vacuolar degeneration. Despite the treatment with both DMH and VCO most likely led to narrowing of sinusoids and appearance of few vacuolated hepatocytes, regular hepatic architecture was markedly noticed (Figure 2b). More ameliorative features were noticed in the liver tissues of DMH-treated rats that received LA, where normal hepatic lobular structure with healthy hepatocytes was seen in association with very few inflammatory cells (Figure 2c). On the other hand, treatment with 5-FU did not modulate the histological changes induced by $\mathrm{DMH}$ in liver tissues, and there were no signs of improvements (Figure 3a). Focal necrotic areas, especially at the periphery of the central vein, and dilatation of the congested central veins were observed in the liver of $\mathrm{DMH}+5$-FU-treated rats. Also, the cytoplasm of most of the hepatocytes appeared vacuolated, and pyknotic nuclei were observed (Figure 3a). Hepatic tissues of rats treated with $\mathrm{DMH}, 5-\mathrm{FU}$, and either VCO or LA retained normal hepatic architecture. The tissues of the $\mathrm{DMH}+5$-FU + VCO-treated group showed some cytomegalic hepatocytes with a slight narrowing of sinusoids (Figure $3 b$ ). 

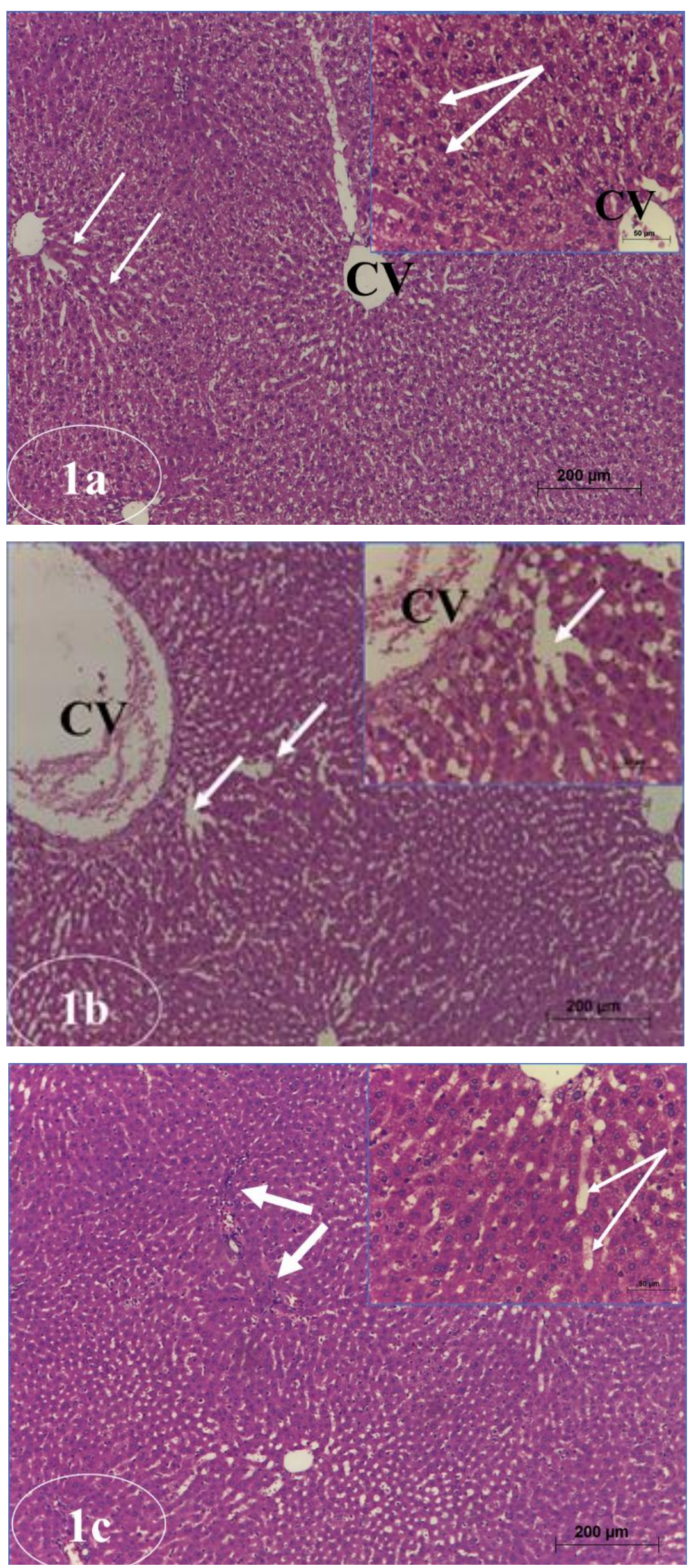

Figure 1: Photomicrographs of liver sections stained with haematoxylin and eosin of the control and natural productstreated groups.

(a) Control group showing normal hepatic cords of hepatocytes, sinusoids (thin arrows), and central veins $(\mathrm{CV})$. The magnified part is showing the hepatocytes with prominent vesicular nuclei (thick arrows).

(b) Virgin coconut oiltreated group showing hepatic parenchyma with some dilatation of the sinusoids (arrows) and slight congestion of the dilated central veins $(\mathrm{CV})$. (c) Lauric acid-treated group showing nearly normal hepatocytes with prominent nuclei, sinusoids (thin arrows), and few inflammatory cells (thick arrows).

Scale bar equals $200 \mu \mathrm{m}$ for low magnification, and $50 \mu \mathrm{m}$ for high magnification. 

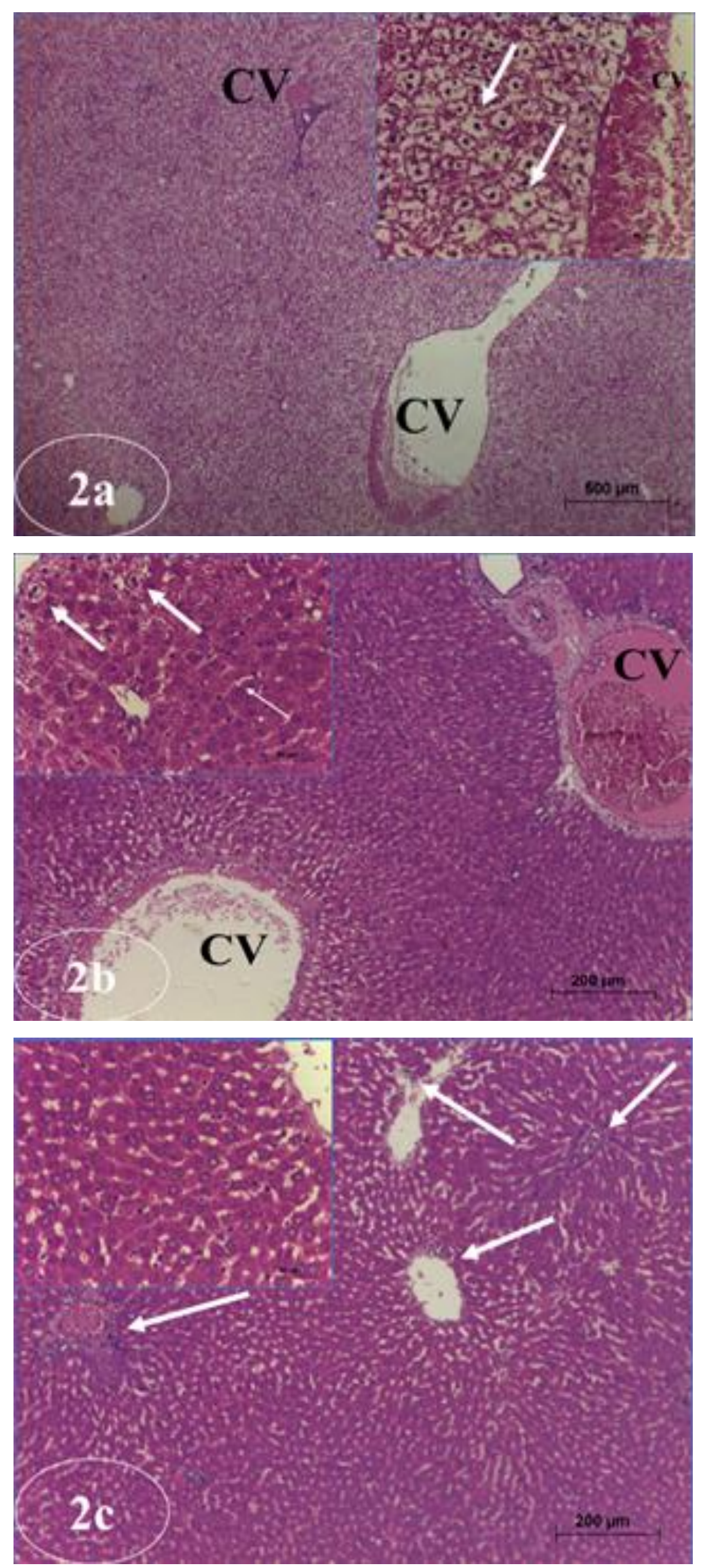

Figure 2: Photomicrographs of liver sections stained with haematoxylin and eosin of the dimethylhydrazine $(\mathrm{DMH})$-treated groups in presence/absence of the natural products.

(a) DMH-treated group showing the disorganized histological structure of the liver, vacuolar degeneration of hepatocytes, pyknotic nuclei (arrow), and congestion of the dilated central vein (CV).

(b) $\mathrm{DMH}+$ virgin coconut oil-treated group showing nearly normal histological structure of hepatic cords, narrowing of sinusoids (thin arrows), some congested central vein $(\mathrm{CV})$, and few vacuolar degenerated hepatocytes (thick arrows).

(c) $\mathrm{DMH}+$ lauric acidtreated group showing nearly normal hepatic architecture of hepatocytes, sinusoids, and few inflammatory cells (arrows).

Scale bar equals 200 and $500 \mu \mathrm{m}$ for low magnification, and $50 \mu \mathrm{m}$ for high magnification. 

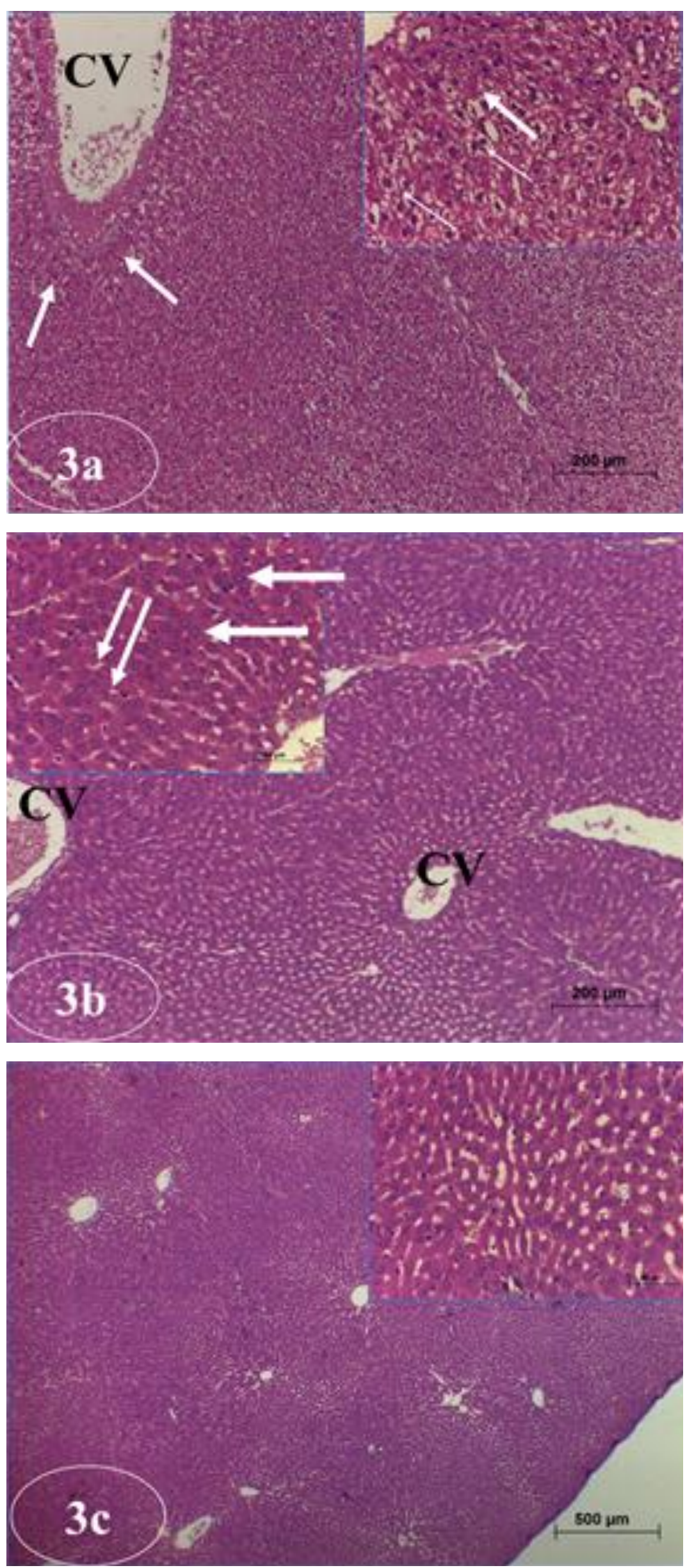

Figure 3: Photomicrographs of liver sections stained with haematoxylin and eosin of the dimethylhydrazine $(\mathrm{DMH})+5$-fluorouracil (5-FU)-treated groups in presence/absence of the natural products.

(a) $\mathrm{DMH}+5$-FUtreated group showing focal necrotic areas (thick arrows), vacuolar degeneration of hepatocytes with pyknotic nuclei (thin arrow), and congestion in the central vein $(\mathrm{CV})$.

(b) $\mathrm{DMH}+5-\mathrm{FU}+$ virgin coconut oil-treated group showing a narrowing of sinusoids (thin arrows), slight enlargement of the hepatocytes (thick arrows), and some congestion in the central veins $(\mathrm{CV})$.

(c) $\mathrm{DMH}+5-\mathrm{FU}+$ lauric acid-treated rats showing normal hepatic architecture.

Scale bar equals 200 and $500 \mu \mathrm{m}$ for low magnification, and $50 \mu \mathrm{m}$ for high magnification. 
On the contrary, treatment with LA + 5-FU preserved intact liver parenchyma, including hepatocytes, sinusoids, and vascular supply in DMH-treated rats (Figure 3c).

\section{DISCUSSION}

The liver is a vital organ with a wide range of metabolic, detoxification, and immune functions ${ }^{[23]}$. The hepatotoxic activity of $\mathrm{DMH}$ shown in the current study was probably due to its ability to generate free radicals ${ }^{[24]}$. DMH is an alkylating agent that is widely used to induce tumours in the colon of rodents ${ }^{[25]}$. Subcutaneously administered DMH released slowly into the circulation, reached the liver, and metabolized into various carcinogenic intermediates $^{[26]}$. According to the current histopathological study, the liver tissues of DMH-treated group showed a high degree of alterations, as necrosis and degeneration of the hepatocytes. Cellular infiltration, vacuolar degeneration, and pyknosis were also seen in the liver tissues of 5-FUinjected group. The 5-FU is used as a chemotherapeutic agent, but its clinical utility is limited by its hepatotoxic side effects $^{[27,28]}$. Several abnormalities in the liver architecture were previously recorded after intraperitoneal administration of 5-FU, including the apoptotic cell death and the appearance of inflammatory cells in different areas $^{[28]}$. In addition, the cytoplasmic organelles were markedly affected, and the collagenous fibrils were found in necrotic cells in 5-FU-treated animals ${ }^{[27]}$.

The elevation in the activity of serum aminotransferases, especially ALAT, is commonly used to detect the liver cellular damage $^{[29]}$. In the current study, the histological findings are in consistent with the biochemical results, where the treatment with DMH led to an increase in the activity of ALAT and ASAT in the rats' sera. On the other hand, the treatment with VCO or LA after DMH injection decreased the activity of these enzymes in serum, which could explain the hepatoprotective role of these natural products.
When electrons from different systems penetrate oxygen in a living organism, the ROS are produced ${ }^{[30]}$. The cellular defence plays an essential role in alleviating tissue damage caused by free radicles ${ }^{[30]}$. ROS has a direct effect on various biological components. It causes cellular damage and necrosis in the liver ${ }^{[31]}$. The getting rid of ROS is carried out by a radicle scavenging system such as CAT, SOD, and a reduced GSH. The 5-FU induced an increase in the amount of ROS and the level of MDA in the liver tissues ${ }^{[32]}$. A reduction in the activity of vital antioxidant enzymes (including SOD and CAT) in the liver was also demonstrated following treatment with 5-FU ${ }^{[33]}$. Earlier report revealed that the enhancing levels of tissue lipid peroxidation, along with the lowering of tissue SOD and CAT activities, indicated an increase in the oxidative stress during DMH-induced carcinogenesis ${ }^{[34]}$. The current study demonstrated that SOD and CAT activities decreased significantly in the liver of DMH-treated rats as compared with the control rats, which in turn might have contributed to enhance the liver lipid peroxidation in the DMH-treated rats. A decrease in the activities of SOD and CAT in $\mathrm{DMH}$ alone-treated rats could also be attributed to the fact that $\mathrm{DMH}$ produces free radicals, which overwhelm the efficacy of the liver antioxidant defence system. In the same point, DMH and VCO co-treatment increased the activity of these enzymes. This finding could be taken in consideration because VCO acts as a free radical scavenger and modulator of antioxidant enzymes $^{[35]}$. The decrease in tissue GSH levels in rats treated with DMH was also reported in the current study and other previous studies ${ }^{[34]}$. The reduction in the levels of tissue GSH may be due to the insult of $\mathrm{DMH}$, which increases and multiply free radicals, thereby decreasing or overstressing the cellular $\mathrm{GSH}^{[34,24]}$. Karthik Kumar et $a l^{[36]}$ also reported an increase in the levels of tissue lipid peroxidation in the DMH-treated groups. In the current study, the DMH-induced hepatic lipid peroxidation and oxidative stress were 
decreased significantly in the VCO and LA (with/without 5-FU) supplemented groups.

On the histological level, a significant recovery and preserving of the hepatic architecture were observed in the DMHtreated groups supplemented with VCO and LA (with/without 5-FU). Zakaria et al. $(2011)^{[37]}$ also reported that VCO reduced liver damage induced by paracetamol. Improved liver antioxidant defence system of animals received $\mathrm{VCO}$ alone or combined with 5-FU, as noted in the present study, may be responsible for the hepatoprotective effects shown on the histological level.

VCO is more abundant in phytonutrients and polyphenols than the commonly used refined oil ${ }^{[38]}$. Supplementation of VCO has been reported to have beneficial effects on lipid metabolism by reducing lipogenesis and enhancing the rate of fatty acid catabolism in rats ${ }^{[15]}$. Chemoprotective, antiinflammatory, and antipyretic activities of VCO were also reported previously ${ }^{[39-42]}$. LA constitutes about $52 \%$ of $\mathrm{VCO}$; it also had cholesterol lowering activity ${ }^{[43]}$. LA is a saturated medium-chain fatty acid of coconut oil; such fatty acids are the structural components of the cellular membranes either alone or together with other molecules as phospholipids and triacylglycerols ${ }^{[44]}$. In addition, fatty acid oxidation occurring at the mitochondrial level plays a vital role in maintaining energy homeostasis during catabolic states ${ }^{[45]}$. Moreover, the saturated fatty acids as LA may influence the biosynthesis of cholesterol and triacylglycerols, the assembly and secretion/clearance of lipoproteins, various metabolic and inflammatory processes through regulating transcription factors involved in lipid metabolism and inflammation $^{[43,44]}$.

In conclusion, the histopathological results were in agreement with the biochemical results and confirmed that the VCO and LA have hepatoprotective activity. Either administration of these natural products alone or in combination with 5-FU in DMH-treated rats resulted in preserving the hepatic parenchyma and the lobular structure of the liver tissues nearly the normal architecture. In addition, VCO and LA treatment alleviated the liver oxidative stress and injury caused by DMH in rats, where both agents had enhanced the restoration of the biochemical and histological configuration. It is worth mentioning that $\mathrm{VCO}$ and LA were more protective agents than 5-FU against hepatic toxicity induced by $\mathrm{DMH}$.

\section{ACKNOWLEDGMENTS}

This study received no specific grant from any funding agency in public, commercial, or not-for-profit sectors.

\section{CONFLICT OF INTEREST}

The authors have no potential financial conflict of interest.

\section{REFERENCES}

[1] Nomura, K.; Schlake, W. and Grundmann, E. (1978). New aspects of intestinal carcinogenesis by 1,2dimethylhydrazine dihydrochloride $(\mathrm{DMH})$ and the influence of antilymphocyte globuline (ALG) on its progress. Z Krebsforsch Klin Onkol Cancer Res Clin Oncol, 92: 17-33.

[2] Liu, Y. Y.; Schmeltz, I. and Hoffmann, D. (1974). Chemical studies on tobacco smoke. Quantitative analysis of hydrazine in tobacco and cigarette smoke. Anal Chem, 46(7): 885-889.

[3] Druckrey, H. (1972). Organospecific carcinogenesis in the digestive tract. In: Topics in Chemical Carcinogenesis (Nakahara, W.; Takayama, S.; Sugimura, T. et al., eds), pp. 73-101. Tokyo University Press, Tokyo, Japan.

[4] Swenberg, J. A.; Cooper, H. K.; Bücheler, J. et al. (1979). 1,2Dimethylhydrazine-induced methylation of DNA bases in various rat organs and the effect of pretreatment with disulfiram. Cancer Res, 39: 465467.

[5] Sharma, K. K.; Pathak, R. M.; Sharma, V. et al. (1995). Effects of 
orally administered 1,2-dimethylhydrazine on the absorptive activities of small intestine of mouse. Res Bull, 45(1-4): 11-17.

[6] Glauert, H. P. and Bennink, M. R. (1983). Metabolism of 1,2-dimethylhydrazine by cultured rat colon epithelial cells. Nutr Cancer, 5(2): 7886.

[7] Abdella, E. M.; Mahmoud, A. M. and El-Derby, A. M. (2016). Brown seaweeds protect against azoxymethane-induced hepatic repercussions through upregulation of peroxisome proliferator-activated receptor gamma and attenuation of oxidative stress. Pharmaceutical Biology, 54(11): 24962504.

[8] Bannasch, P.; Haertel, T. and Su, Q. (2003). Significance of hepatic preneoplasia in risk identification and early detection of neoplasia. Toxicol pathol, 31: 134-139.

[9] El-Naggar, S. A.; Ibrahim, M. A.; El-Tantawi, H. G. et al. (2018). Pretreatment with the micro-alga, Spirulina platensis ameliorates cyclophosphamide-induced hematological, liver and kidney toxicities in male mice. Ain Shams Journal of Forensic Medicine and Clinical Toxicology, 30: 1-7.

[10] Lee, J. J.; Beumer, J. H. and Chu, E. (2016). Therapeutic drug monitoring of 5-fluorouracil. Cancer Chemother Pharmacol, 78(3): 447-464.

[11] Shoemaker, L. K.; Arora, U. and Rocha Lima, C. M. (2004). 5-Fluorouracil-induced coronary vasospasm. Cancer Control, 11: 46-49.

[12] El-Naggar, S. A.; Alm-Eldeen, A. A.; Germoush, M. O. et al. (2015). Ameliorative effect of propolis against cyclophosphamide induced toxicity in mice. Pharm Biol, 53(2): 235-241.

[13] El-Naggar, S. A.; Abdel-Farid, I. B.; Germoush, M. O. et al. (2016). Efficacy of Rosmarinus officinalis leaves extract against cyclo- phosphamide-induced hepatotoxicity. Pharm Biol, 54(10): 2007-2016.

[14] Marina, A. M.; Che Man, Y. B.; Nazimah, S. A. et al. (2009). Antioxidant capacity and phenolic acids of virgin coconut oil. Int J Food Sci Nutr, 60(Suppl 2):114-123.

[15] Arunima, S. and Rajamohan, T. (2012). Virgin coconut oil improves hepatic lipid metabolism in rats-compared with copra oil, olive oil and sunflower oil. Indian J Exp Biol, 50(11): 802-809.

[16] Hlongwane, C.; Delves, I. G.; Wan, L. W. et al. (2001). Comparative quantitative fatty acid analysis of triacylglycerols using matrix-assisted laser desorption/ionization time-offlight mass spectrometry and gas chromatography. Rapid Commun Mass Spectrom, 15(21): 2027-2034.

[17] Calder, P.C. (2011). Fatty acids and inflammation: the cutting edge between food and pharma. Eur $\mathbf{J}$ Pharmacol, 668: S50-S58.

[18] Fauser, J. K.; Matthews, G. M.; Cummins, A. G. et al. (2013). Induction of apoptosis by the mediumchain length fatty acid lauric acid in colon cancer cells due to induction of oxidative stress. Chemotherapy, 59(3): 214-224.

[19] Huang, W. C.; Tsai, T. H.; Chuang, L. T. et al. (2014). Anti-bacterial and anti-inflammatory properties of capric acid against Propionibacterium acnes: a comparative study with lauric acid. J Dermatol Sci, 73(3): 232-240.

[20] Temme, E. H.; Mensink, R. P. and Hornstra, G. (1996). Comparison of the effects of diets enriched in lauric, palmitic, or oleic acids on serum lipids and lipoproteins in healthy women and men. Am J Clin Nutr, 63(6): 897-903.

[21] Alves, N. F.; de Queiroz, T. M.; de Almeida Travassos, R. et al. (2017). Acute treatment with lauric acid reduces blood pressure and oxidative stress in spontaneously hypertensive rats. Basic Clin Pharmacol and Toxicol, 120(4): 348-353. 
[22] Bancroft, J. D. and Gamble, M. (2008). Theory and Practice of Histological Techniques. Churchill Livingstone/Elsevier, Philadelphia, PA, USA.

[23] Racanelli, V. and Rehermann, B. (2006). The liver as an immunological organ. Hepatology, 43(2 Suppl 1): S54-S62.

[24] Khan, R. and Sultana, S. (2011). Farnesol attenuates 1,2-dimethylhydrazine induced oxidative stress, inflammation and apoptotic responses in the colon of Wistar rats. Chem Biol Interact, 192(3): 193-200.

[25] Cooper, H. K.; Buecheler, J. and Kleihues, P. (1978). DNA alkylation in mice with genetically different susceptibility to 1,2-dimethylhydrazine-induced colon carcinogenesis. Cancer res, 38(9): 3063-3065.

[26] Fiala, E. S. (1977). Investigations into the metabolism and mode of action of the colon carcinogens 1,2-dimethylhydrazine and azoxymethane. Cancer, 40: 2436-2445.

[27] El-Sayyad, H. I.; Ismail, M. F.; Shalaby, F. M. et al. (2009). Histopathological effects of cisplatin, doxorubicin and 5-flurouracil (5-FU) on the liver of male albino rats. Int $\mathbf{J}$ Biol Sci, 5(5): 466-473.

[28] Zorzi, D.; Laurent, A.; Pawlik, T. M. (2007). Chemotherapy-associated hepatotoxicity and surgery for colorectal liver metastases. $\mathrm{Br} \mathrm{J}$ Surg, 94(3): 274-286.

[29] King, P. D. and Perry, M. C. (2001). Hepatotoxicity of chemotherapy. Oncologist, 6(2): 162-176.

[30] Stockham, S. L. and Scott, M. A. (2008). Fundamentals of Veterinary Clinical Pathology. Blackwell, Ames, IA, USA.

[31] Zeashan, H.; Amresh, G.; Singh, S. et al. (2009). Hepatoprotective and antioxidant activity of Amaranthus spinosus against $\mathrm{CCl} 4$ induced toxicity. J Ethnopharmacol, 125(2): 364-366.
[32] Ali, N. E. M. (2012). Protective effect of captopril against 5-fluorouracilinduced hepato and nephrotoxicity in male albino rats. Journal of American Science, 8(2): 680-685.

[33] Afolabi, O. K.; Adeleke, G. E. and Ugbaja, R. N. (2016). Crocin alleviates 5-fluorouracilinduced hepatotoxicity through the abrogation of oxidative stress in male Wistar rats. Asian Pac J Health Sci, 3(2): 58-68.

[34] Hamiza, O. O; Rehman M. U.; Tahir, M. et al. (2014). Methanolic extract of Terminalia chebula protects against DMH-induced colon damage in Wistar rats by restoring antioxidant enzyme activities and suppressing inflammation. Int J Drug Dev \& Res, 6: 54-69.

[35] Narayanankutty, A.; Palliyil, D. M.; Kuruvilla, K. et al. (2018). Virgin coconut oil reverses hepatic steatosis by restoring redox homeostasis and lipid metabolism in male Wistar rats. J Sci Food Agric, 98(5): 17571764.

[36] Karthik Kumar, V.; Vennila, S. and Nalini, N. (2010). Inhibitory effect of morin on DMH-induced biochemical changes and aberrant crypt foci formation in experimental colon carcinogenesis. Environ Toxicol Pharmacol, 29: 50-57.

[37] Zakaria, Z. A.; Rofiee, M. S.; Somchit, M. N. et al. (2011). Hepatoprotective activity of dried- and fermentedprocessed virgin coconut oil. Evid Based Complement Alternat Med, 2011: 142739 (DOI: 10.1155/2011/ 142739).

[38] Otuechere, C. A.; Madarikan, G.; Simisola, T. et al. (2013). Virgin coconut oil protects against liver damage in albino rats challenged with the antifolate combination, trimethoprimsulfamethoxazole. J Basic Clin Physiol Pharmacol, 25(2): 249253. 
[39] Vysakh, A.; Ratheesh, M.; Rajmohanan, T. P. et al. (2014). Polyphenolics isolated from virgin coconut oil inhibits adjuvant induced arthritis in rats through antioxidant and anti-inflammatory action. Int immunopharmacol, 20:124-130

[40] Yeap, S. K.; Beh, B. K.; Ali, N. M. et al. (2015). Antistress and antioxidant effects of virgin coconut oil in vivo. Exp Ther Med, 9: 39-42.

[41] Nair, S. S.; Manalil, J. J. and Ramavarma, S. K. et al. (2016). Virgin coconut oil supplementation ameliorates cyclophosphamideinduced systemic toxicity in mice. Hum Exp Toxicol, 35(2): 205-212.

[42] Famurewa, A. C.; Ufebe, O. G.; Egedigwe, C. A. et al. (2017). Virgin coconut oil supplementation attenuates acute chemotherapy hepatotoxicity induced by anticancer drug methotrexate via inhibition of oxidative stress in rats. Biomed Pharmacother, 87: 437-442.

[43] Lekshmi Sheela, S. D.; Nazeem, P. A.; Narayanankutty, A. et al. (2016). In silico and wet lab studies reveal the cholesterol lowering efficacy of lauric acid, a medium chain fat of coconut oil. Plant Foods Hum Nutr, 71(4): 410-415.

[44] Ibarguren, M.; López, D. J. and Escribá, P. V. (2014). The effect of natural and synthetic fatty acids on membrane structure, microdomain organization, cellular functions and human health. Biochim Biophys Acta, 1838(6):1518-1528.

[45] Fukui, M.; Kang, K.S.; Okada, K. et al. (2013). EPA, an omega-3 fatty acid, induces apoptosis in human pancreatic cancer cells: role of ROS accumulation, caspase- 8 activation, and autophagy induction. J Cell Biochem, 114: 192203.

\section{How to cite this article:}

El-Bagoury, A. A.; El-Tantawi, H. G.; El-Naggar, S. A.; Kwilla, A. M. and Khalaf A. M. (2019). Effects of virgin coconut oil and lauric acid "with or without 5-fluorouracil" on dimethylhydrazineinduced hepatotoxicity in male rats. Egyptian Journal of Zoology, 71: 56-69 (DOI: 10.12816/ejz.2019.63568). 


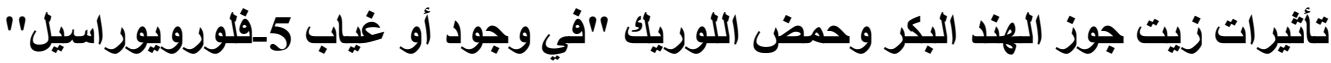

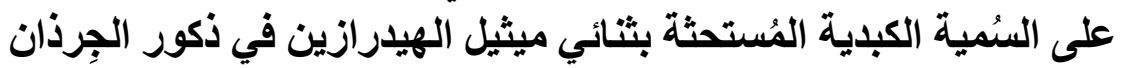

\section{عادل عبد الحميد الباجوري، هالة جلال الطنطاوي، صبري علي النجار، أمل محمد كويلة1، أمل محمد خلف 1 المنط}

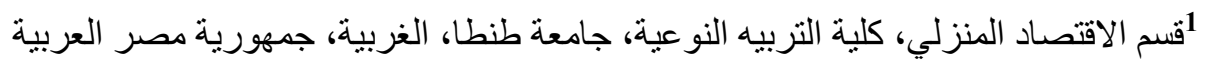

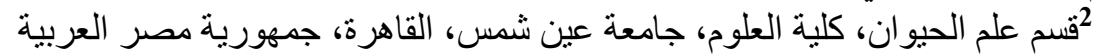

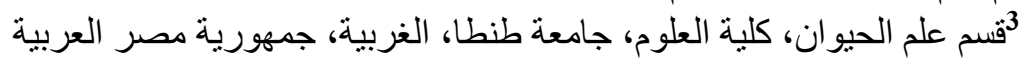

يُعتبر "ثثائي ميثيل الهيدر ازين" من المركبات شديدة السُمية على أعضاء الجسم، بما في ذللك الكبد. هدفت الدر اسة الحالية

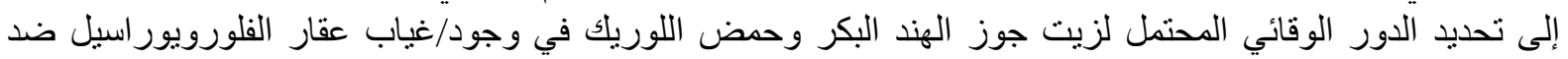

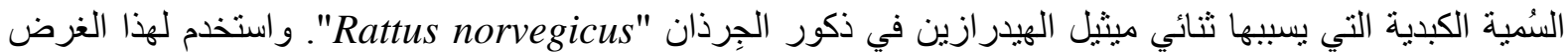

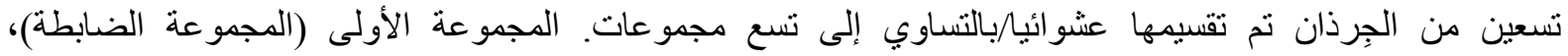

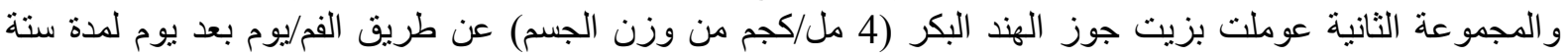

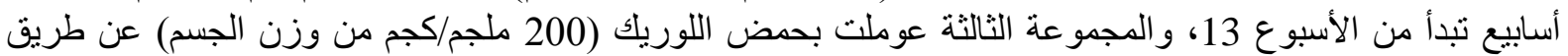

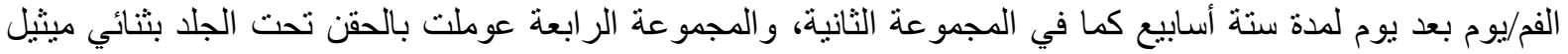

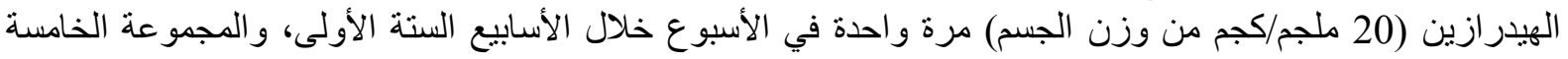

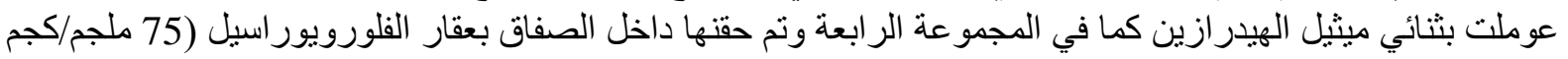

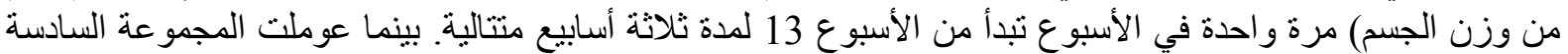

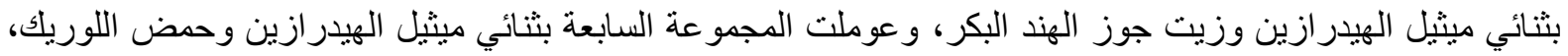

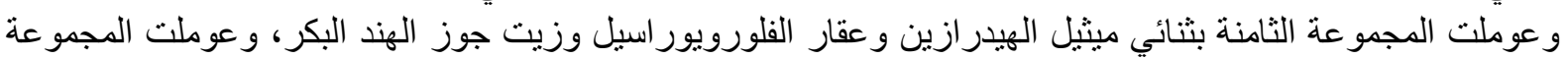

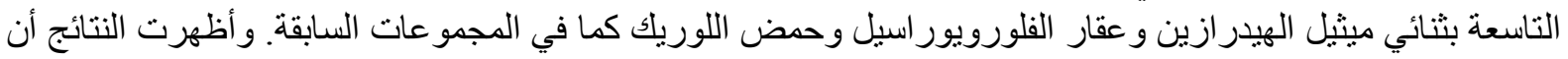

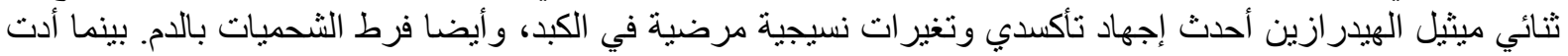

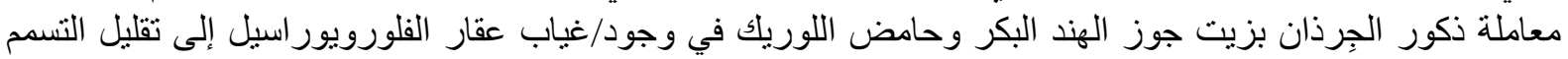
الكبدي الناجم عن ثنائي ميثيل الهيدر ازين. 